\section{PUERPERAL FEVER.}

By F. CHURCHILL, M.D., M.R.I.A., Fellow and Ex-President of the King and Queen's College of Physicians in Ireland.

I READ with great interest the report of the debate on Puerperal Fever at the London Obstetrical Society. Amidst a good deal of somewhat vague theorising as to the essential nature of the fever, and its relations to other zymotic diseases, one practical point seemed to stand out rather prominently; viz., that a (if not the) principal mode of the spread of that terrible disease, is its conveyance by the medical attendant, from one patient to another. That this impression was produced upon others as well as myself, is proved by the fact that two letters at least have since appeared in the Jou RNAL attempting to fix a period of quarantine for all doctors who have a patient so attacked, in which attempt they have been seconded by a coroner's jury, whatever its opinion may be worth. Such a question, therefore, cannot be confined to the debates of the Obstetrical Society, but must percolate through society generally, creating great alarm and seriously injuring medical men. If this opinion be true, of course, those consequences cannot be avoided ; but, before coming to such a conclusion, it appears to me that we should possess more extensive and more precise information than we have at present, and, if an old practitioner be of no other use, he may at least be allowed to plead for delay and further consideration.

Let us see upon what ground we stand.

1. We know that a person going direct from a post mortem examination to a lying-in case may excite puerperal fever in that patient. But how often does the opportunity for such mischief occur? I should suppose that most obstetricians do as I used to do ; viz., ask a friend to make the post mortem examination for me; but, if in the country parts this be impracticable, surely it must be very rarely that the post mortem examination and the delivery succeed each other immediately.

2. We know that medical men attending cases of erysipelas have excited puerperal fever from attending lying-in women at the same time, especially if, as has happened, due precautions had not been taken.

3. We know that nurses going from attending on puerperal fever to lying-in women have conveyed the disease. But it must be remembered that a nurse attending on a case of puerperal fever comes into very close contact with the patient, and her hands have to do with the discharges and with whatever may be unhealthy about the genitals, and this at least once every day ; so that it would require extraordinary care to avoid conveying morbid matter to the vaginal mucous membrane of the parturient woman.

4. We also know that, in some cases, the disease has followed in the track of some particular doctor, and that, in spite of minute and thorough precautions, as in the case of Dr. Gooch's friend and the American physician mentioned by Holmes and Dewees.

How to explain such cases, I confess I do not know. But very few such are on record, nor do I think they can be used to prove the necessity of quarantine; they rather show its failure.

5. All men in large obstetric practice meet occasionally with cases of puerperal fever. Dr. Dewees met with a number of such ; but, in a passage too long for quotation, he has given the dates of their occurrence, showing conclusively that he could not have transported the complaint ; and he mentions that he met in consultation the physician who was haunted by the disease, with perfect immunity as regards his own patients.

6. In the course of forty years of practice, I have had puerperal fever among my patients; but the most rigid inquiry has failed to shew me any connection between any two patients. The precautions I adopted were these. I never attended a confinement in the clothes I had worn on my visits. I always saw recently confined patients before seeing the fever case, and, on returning home, I always changed my clothes. I was scrupulously careful about the frequent and thorough washing of my hands before leaving the patient's house. So far as I was concerned, these precautions were successful ; for I certainly never carried the disease from one patient to another. If they had failed, it would have been difficult to say how the disease had been conveyed. If the dress and hands were out of the question, it must have been by some absorption of the "contagium".

7. If the ordinary attendant is to be put in quarantine, what about the consultant?. Is he not as likely to carry infection? Yet we never hear of his doing so, and no one refuses to see these cases and yet attend his own lying-in patients.

Taking into consideration all these points, and before we assume the portability of the disease, I hope that some effort will be made to col- lect examples to show how often, notwithstanding due precautions, the sequence of the disease proves it to have been conveyed from one patient to another by a third person. If well authenticated cases of this kind be numerous, then puerperal fever is more infectious than typhus, scarlatina, or even plague, and the doctors must go into quarantine. If not, neither the profession nor the public need be alarmed, and, with proper precautions, the doctors may pursue their avocations in peace and security.

\section{WHAT IS THE DURATION OF QUARANTINE REQUIRED AFTER PUERPERAL FEVER?}

By A. D. L. NAPIER, M.B., C.M., Fraserburgh, N.B.

In the British Medichl Journal of January 22nd, Dr. Braxton Hicks has invited discussion on the above-named question. The disease is inferred to be always contagious; Dr. Hicks evidently ignoring the idea of epidemic puerperal fever as a reality. Without wasting time in specious arguments, I simply deny the correctness of this hypothesis. I could easily prove that the disease was generally epidemic. I do not wish to systematise or theorise, as most authorities on this subject are too apt to do, but will simply give unvarnished facts.

I have in my possession notes of thirty-one cases, of which twentythree were under my own care. I have formerly published twentytwo of the thirty-one cases. I do not think it necessary to instance midwifery cases which were attended by myself shortly after treating a case of fever, when these patients were in course of time seized with fever; of these I had a few examples, but that is not the point raised.

The question to answer is, How long must we abstain from obstetric practice after attending a case of puerperal fever? As Dr. Braxton Hicks uses the word accoucheur, I presume the question more exactly is, If a medical man deliver a woman who is attacked with puerperal fever, how long time must elapse before he can with safety deliver another patient? To prove the extreme uncertainty of the accuracy of any hard and fast law to guide us in our rules of the requisite quarantine, I will cite a few instances.

On December 8th, 1874, I delivered a primipara, who died of puerperal fever on December I 3 th. I treated a case of puerperal fever from December I6th to December 3Ist. This woman had been delivered by a midwife on December $13^{\text {th }}$, and died on December 22nd. I refused all midwifery till January 24 th, 1875 , when I attended another woman. She had a tedious labour, which was terminated by forceps; she grew ill on January $25^{\text {th }}$ with puerperal fever, and was cured on February 7 th, after a severe illness.

On February 2oth, I attended a difficult case, which was followed by good recovery; no fever. On March 5 th, I delivered a woman. This patient had puerperal fever, with subsequent oophoritis; she was cured in May. Having had several cases prior to this, I left off practice from March 9th till April 29th, when, returning home, I delivered a patient, who died six days after her confinement. On May 2Ist, I had a severe forceps case ; on May 29th, a breech case, besides others; all did well. These are cases with long intervals, let us analyse them.

The first was delivered on December 8th, 1874 ; the second I did not deliver; the third was delivered on January 24 th, 1875 ; so that there was an interval of forty-seven days. The next case, less than a month afterwards, had no fever, but made a good recovery ; the fourth, a woman confined on March 5 th, forty-one days from January 24 th, took fever; the fifth case quoted, took fever fifty-six days after the case preceding it.

In July, 1875 , puerperal fever again broke out after we had enjoyed a perfect immunity from it. Thus, we had an interval of three months. At this time, as at the former, cases occurred not only in my practice, but in the hands of other practitioners also.

Now for the other side of the question. On July 2 Ist, I attended a woman in childbed, who took puerperal fever. I treated her till August 8th, when she had recovered; I had also under my care from July 2 th to August 2nd, a mild case of the fever. On August 4th, I attended a case of midwifery; the recovery was excellent. On August 28th, I delivered a woman who took the fever, and recovered on September 9th. On August 3 Ist, I had a very difficult forceps case, in a second labour ; the woman made an excellent recovery. On Sep-

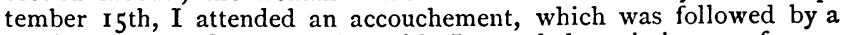
good recovery. On September I6th, I attended a primipara, a forceps case; the woman had puerperal fever, and died September 23rd. On September $20 t h$, I attended a case of labour, followed by good recovery. On September 3oth, I treated a woman for puerperal fever, who had been delivered by a midwife on September 28th ; she reco- 